\title{
Reliability and validity of the Spinal Appearance Questionnaire (SAQ) and the Trunk Appearance Perception Scale (TAPS)
}

\author{
Meinald T. Thielsch ${ }^{1 *}$ (D), Mark Wetterkamp², Patrick Boertz ${ }^{1}$, Georg Gosheger ${ }^{3}$ and Tobias L. Schulte ${ }^{2}$
}

\begin{abstract}
Background: The Spinal Appearance Questionnaire (SAQ) and the Trunk Appearance Perception Scale (TAPS) are questionnaires that mostly rely on drawings to assess scoliosis patients' subjective viewpoints on their trunk deformity. Our aim was to perform an in-depth assessment of the psychometric quality of both measures, the SAQ (version 1.1) and TAPS, and compare them to provide practical recommendations.

Methods: Web-based survey study with 255 patients suffering from idiopathic scoliosis (age 30.0 \pm 16.7 years, Cobb angle $43.5 \pm 20.9^{\circ}$ ) and 189 matched healthy control individuals. Participants answered a broad set of validated questionnaires including SRS 22-r, PHQ-9, PANAS, FKS, WHO-5, BFI-S, and PTQ. We calculated reliability (Cronbach's a, test-retest correlations) as well as factorial, convergent, divergent, concurrent, and discriminant validity.

Results: Reliability was high (Cronbach's $a \geq .86$; test-retest $r \geq .80$ ), except for test-retest correlation of the SAQ Expectations scale $(r=0.67)$. Both the SAQ and TAPS measures showed clear factor solutions, indicating factorial validity. High correlations with theoretically related measures (e.g., SRS 22-r, overall stress, Cobb angle) indicated convergent validity. Moderate correlations occurred with concurrent criteria such as mood, depression, body dysmorphic disorder, and well-being. The matched-pair analysis revealed strong evidence for discriminant validity (Cohen's $d>2$ for SAQ total score and TAPS). Subgroup analyses showed that patients with more severe Cobb angles $\left(\geq 40^{\circ}\right)$ and those $\geq 46$ years of age had significantly worse SAQ and TAPS scores.
\end{abstract}

Conclusion: We recommend using the TAPS for future clinical workups and research, as it is much shorter and revealed slightly higher psychometric quality in comparison to the SAQ.

Keywords: Idiopathic scoliosis, Body image, Assessment, Psychometric properties, Validation

\section{Background}

In recent years, specific scales for the in-depth evaluation of scoliosis patients' subjective viewpoints on their trunk deformity have been developed [1-3]. Most of such scales use questions in the form of statements, yet two specific instruments encompass drawings: The Spinal Appearance Questionnaire (SAQ) and the Trunk Appearance Perception Scale (TAPS), both originating from the Walter Reed Visual Assessment Scale (WRVAS) [4-6].

\footnotetext{
* Correspondence: thielsch@uni-muenster.de

${ }^{1}$ Department of Psychology, University of Münster, Fliednerstr. 21, 48149

Münster, Germany

Full list of author information is available at the end of the article
}

The WRVAS focuses on patients' appearances, but it fails to ask about patients' satisfaction with their body image [6]. Also, as reported by Bago et al., some of the WRVAS drawings do not directly correlate with the equivalent radiological deformity, and adolescents can have difficulties in comprehending the questionnaire [5, 7]. Therefore, Sanders et al. created the SAQ, which was further modified by Carreon et al. to address these specific limitations $[4,8]$. This current modified version of the SAQ, the SAQ v1.1, is the focus of the present study; for readability, we will refer to it only as SAQ (meaning SAQ v.1.1) in the following text. This questionnaire consists of 11 pictorial items and 22 questions regarding patients' expectations. Yet, based on data from 1802 patients, Carreon et al. found that only 14 of the items

(c) The Author(s). 2018 Open Access This article is distributed under the terms of the Creative Commons Attribution 4.0 International License (http://creativecommons.org/licenses/by/4.0/), which permits unrestricted use, distribution, and 
loaded on two factors: The first ten drawings on the so-called Appearance factor and four questions (\#12-15) on an Expectations factor. Thus, the authors recommended using only these 14 items. The authors also reported evidence for good reliability (Cronbach's $\alpha \geq 0.88$; test-retest correlation $\geq 0.81$ ) and convergent validity of the SAQ in terms of correlations with the major curve magnitude $(0.324 \leq r \leq 0.361, P<0.01)$, and they argued for discriminant validity by showing significant differences between patients receiving different treatments [8]. Yet, they have not yet performed a comparison with healthy controls or a systematic analysis of further convergent criteria (especially psychological criteria and patients' well-being). Furthermore, Mulcahey et al. [7] found that a large percentage of younger patients (between 8 and 16 years old) had difficulties understanding items and illustrations in the child version of the SAQ. Finally, there is an imbalance between the SAQ Appearance and the SAQ Expectation scales, as the Appearance scale makes up about $70 \%$ of the total SAQ score. Thus, in psychometric analyses, both subscales should be examined in detail and separately.

The other questionnaire of interest in this study, the TAPS, was created by Bago et al. [5]. It consists of only three drawings illustrating the patient's trunk from three different angles: First, looking at the back of the patient in an upright position; second, looking at the front of the patient from their head towards the pelvis while the patient is bent over towards the observer; and third, looking at the front of the patient in an upright position (this third drawing has a version for females and a version for males) [9]. The authors tested 186 patients and found evidence for good to excellent reliability (Cronbach's $\alpha=0.89$; test-retest correlation for $n=35$ patients was 0.92). Furthermore, Bago et al. reported convergent validity in terms of high correlations with the SRS-22 and discriminant validity by finding high correlations between TAPS and the largest curve in terms of Cobb angle (CMAX) [5]. In additional studies, Misterka et al. reported high correlations between TAPS and the main Cobb angle $(r=-0.44, P<0.05, n=36)$ [10]; Rigo et al. reported high correlations between TAPS and self-image and pain scales in the SRS-22 $(n=71)$ [11]. Nonetheless, currently, the TAPS has only been assessed with relatively small samples; it is still missing a factor analysis, a comparison to healthy controls, and further systematic analysis of additional convergent criteria.

Matamalas et al. was the first to directly compare the SAQ with the TAPS based on a sample of 80 patients (with Cobb angles $\geq 25^{\circ}$, mean age 20.3 years). They found nearly identical reliability values (in terms of Cronbach's $\alpha$ ) as the original studies, high correlation with the SRS-22 and with radiological magnitude of the curve, and a correlation of $r=-0.80$ between the SAQ
Appearance scale and TAPS. Matamalas et al. favored the TAPS over the SAQ because it is shorter [12]. Still, to validly compare the SAQ and the TAPS, there needs to be a broad prospective cohort study that (a) examines patients of different ages with a wide range of Cobb angles and (b) compares the SAQ (in its version 1.1) with the TAPS using a set of relevant convergent validity criteria, tests the factor structure, and investigates discriminative validity with a matched healthy control sample. Without such a study, it is impossible to further assess the psychometric quality of both instruments and their applicability in practice and research. As a consequence, the first aim of the present study is to assess the reliability and validity of SAQ and TAPS in detail, based on a large clinical sample and a matched healthy control group. The second aim is to compare both instruments in terms of their quality and provide recommendations for their use in research or by physicians.

\section{Materials and methods}

Patients were recruited from the Department of Orthopaedics at Münster University Hospital in Münster, Germany, and from the self-help group for scoliosis patients in Germany (Bundesverband Skoliose-Selbsthilfe e.V.). The online panel PsyWeb (http://psyweb.uni-muenster.de/) was used to establish a healthy control group. Participation in the study required a minimum age of 14 years and was completely voluntary, anonymous, and without any compensation. Informed consent was obtained from all individual participants included in the study. All participants were instructed at the beginning of the online survey about the purpose and responsible researcher (including contact opportunities), that all data will be used only for academic purposes, and that all participants will remain completely anonymous in this study. We asked for consent twice: (1) On the second and third page of the web survey information, consent forms were given. (2) Additionally, all participants were again asked for consent at the end of the study (thus, after they have seen all relevant questions). At this point, participants had the opportunity to withdraw their consent with a self-exclusion item. Data was acquired through self-reports, and data transfer was encrypted. The ethics committee of the Medical Faculty of the University of Münster approved the study (ref. no. 2014-660-f-S).

All study participants were surveyed about their age, gender, height, weight (body mass index was calculated), average level of back pain during the previous 6 months on the visual analogue scale (VAS), current degree of scoliosis (Cobb angle of the most severe curve), history of scoliosis treatment, and current treatment. Afterwards, participants answered several scoliosis-related questionnaires including the SAQ and TAPS. In the SAQ, the first 11 items consist of standardized drawings showing the 
varying severity of several components of spinal deformity [8]. There are five response options (1-5) with a higher score indicating a more severe deformity. The questionnaire goes on with 22 questions concerning patients' impressions regarding their appearance with the following answer options (patients choose one): Not true (1), A little true (2), Somewhat true (3), Fairly true (4), and Very true (5). A higher score indicated a worse deformity [8]. The answers to drawings 1 to 10 result in the SAQ Appearance score and questions 12 to 15 in the SAQ Expectations score [8]. Answers to questions/drawings 1 to 10 and 12 to 15 give the SAQ total score (see scoring sheet in Additional file 1: Appendix 1). Sum scores and, for better comparability of the scales, additional mean scores were calculated (Table 1). The TAPS consists of three drawings scored from 1 (greatest deformity) to 5 (smallest deformity), and a mean score is obtained by adding the scores for the three drawings and dividing by 3 (see Additional file 1: Appendix 2). The SAQ Appearance scale and the TAPS are non-verbal. The four verbal items of the SAQ Expectations scale (as well as additional, not analyzed SAQ items and instructions) were systematically translated by a professional medical translator into German and retranslated by a different medical translator into English. Both English versions were compared, and no relevant discrepancies were found. The final German version of the SAQ is attached in Additional file 1: Appendix 1.

Furthermore, all participants answered several validated questionnaires including the Scoliosis Research Society 22-r (SRS 22-r) [1], Patient Health Questionnaire (PHQ-9) [13], Positive and Negative Affect Schedule (PANAS; only the negative scale was applied in this study) [14], Questionnaire on Body Dysmorphic Symptoms (Fragebogen körperdysmorpher Symptome, FKS) [15], neuroticism subscale from GSOEP Big Five Inventory (BFI-S) [16], and Perseverative Thinking Questionnaire (PTQ) [17]. The study contained three additional questions created by the authors: (1) Do you think your back's shape will lead to less success in your professional career (job-related worries)? (2) Do you think your back's shape will lead to less satisfaction in your private life (social life-related worries)? (Answer scale for these two questions is Definitely not (1), Rather not (2), Maybe (3), Probably yes (4), and Definitely yes (5)). 3. All in all, how stressed are you by the look of your back (overall stress)? (Answer scale for this question is Not at all (1), A little bit (2), Moderately (3), Very (4), and Extremely (5)). Due to time restrictions, the WHO-5 Well-Being Index (WHO-5) [18] was only added during a retest measure. At the end of each data collection, participants were thanked, had the opportunity to give additional comments, and could exclude their data from subsequent analysis.

The survey was available online between March 2015 and March 2016. Data were partly used in the validation of the German Body Image Disturbance QuestionnaireScoliosis (G-BIDQ-S) [19] and the German Quality of Life Profile for Spinal Disorders (G-QLPSD) [20] but were never previously analyzed with respect to the SAQ or TAPS. Further, G-BIDQ-S [19] and the G-QLPSD [20] have a different focus (patients' specific worries, life quality), following a completely different measurement approach by using verbal items (instead of drawings in SAQ and TAPS), and the main focus of prior publications was an investigation with respect to the success of a German translation; the present paper focuses on psychometric qualities of SAQ and TAPS in general and a recommendation for future application.

Statistical analyses were performed using SPSS, version 23.

\section{Results}

A total number of 677 patients started the questionnaire, yet $n=149$ dropped out before completing it. Further, we excluded $n=181$ who reported a spinal deformity other than idiopathic scoliosis, $n=87$ who reported a Cobb angle below $10^{\circ}$, and $n=5$ who did not give consent for analyzing their data. Thus, questionnaires of 255 patients $(37.67 \%)$ were included. An additional 626 individuals were surveyed as healthy controls without scoliosis (of them, $n=347$ dropped out before completing the questionnaire). This led to a subsample of 189 perfectly matched pairs according to age (full years) and gender (i.e., $74.12 \%$ of analyzed patients could be matched).

As the last item of the TAPS showed different drawings for men and women [5], we checked for gender differences in answering behavior before conducting further analysis. In the present study, no significant difference occurred $\left(M_{\text {men }}=3.03 \pm 1.10 \quad M_{\text {women }}=3.14 \pm 0.93 ; \quad T=-0.67\right.$, $\mathrm{df}=253, P=0.51$ ); thus, item 3 was jointly analyzed for both genders. Basic data, demographics, and the results of the SAQ, TAPS, and the other questionnaires are presented in Table 1.

\section{Reliability}

Reliability was tested in terms of internal consistency (i.e., Cronbach's $\alpha$ ) and test-retest reliability (stability over time, see Table 2). Cronbach's $\alpha$ was 0.93 for the SAQ Appearance scale, 0.86 for SAQ Expectations, and 0.91 for SAQ total score; the TAPS had an internal consistency of 0.86 . Thus, both measures are highly consistent.

The retest was conducted about 8 weeks after the primary test (on average $55.44 \pm 26.32$ days). Participants received SAQ and TAPS again, and at both measurement points, some additional measures not pertinent to the current study. There were no significant differences in the means of the SAQ Expectations scale and SAQ total scores. Yet, the SAQ Appearance scale score was a little lower in 
Table 1 Basic data, demographics, and results of questionnaires in the scoliosis group and control group

\begin{tabular}{|c|c|c|c|}
\hline Parameter & $\begin{array}{l}\text { Scoliosis group } \\
(n=255)\end{array}$ & $\begin{array}{l}\text { Scoliosis subgroup for } \\
\text { matched-pair analysis } \\
(n=189)\end{array}$ & $\begin{array}{l}\text { Controls for } \\
\text { matched-pair } \\
\text { analysis } \\
(n=189)\end{array}$ \\
\hline Age (years) & $30.0 \pm 16.7$ & $33.6 \pm 17.0$ & $33.6 \pm 17.0$ \\
\hline \multicolumn{4}{|l|}{ Gender } \\
\hline Male & 38 & 17 & 17 \\
\hline Female & 217 & 172 & 172 \\
\hline Weight (kg) & $63.1 \pm 11.6$ & $64.1 \pm 11.9$ & $67.7 \pm 14.4^{b}$ \\
\hline Height (cm) & $169.6 \pm 9.5$ & $168.7 \pm 9.0$ & $169.1 \pm 7.1^{c}$ \\
\hline $\mathrm{BMI}\left(\mathrm{kg} / \mathrm{m}^{2}\right)$ & $22.0 \pm 4.0$ & $22.6 \pm 4.2$ & $23.6 \pm 4.7^{d}$ \\
\hline Cobb angle $\left({ }^{\circ}\right)$ & $43.5 \pm 20.9$ & $47.8 \pm 20.3$ & - \\
\hline \multicolumn{4}{|l|}{ Academic level } \\
\hline Secondary school & 13 & 11 & 2 \\
\hline Junior high & 65 & 47 & 18 \\
\hline Technical college entry qualification & 25 & 21 & 10 \\
\hline High school & 83 & 54 & 67 \\
\hline University degree & 69 & 56 & 92 \\
\hline \multicolumn{4}{|l|}{ Scoliosis treatment ${ }^{a}$} \\
\hline Physiotherapy & 222 & 160 & 0 \\
\hline Brace & 182 & 127 & 0 \\
\hline Surgery & 84 & 73 & 0 \\
\hline $\begin{array}{l}\text { SAQ total score (range } 14 \text {, i.e., best, to } 70 \text {, i.e., worst), sum score } \\
\text { (mean, range } 1 \text {, i.e., best, to } 5 \text {, i.e., worst) }\end{array}$ & $37.29 \pm 10.72(2.87 \pm 0.85)$ & $38.58 \pm 11.15(2.94 \pm 0.88)$ & $19.19 \pm 5.06(1.45 \pm 0.50)^{\mathrm{e}}$ \\
\hline $\begin{array}{l}\text { SAQ Appearance (range } 10 \text {, i.e., best, to } 50 \text {, i.e., worst), sum score } \\
\text { (mean, range } 1 \text {, i.e., best, to } 5 \text {, i.e., worst) }\end{array}$ & $23.93 \pm 7.59(2.39 \pm 0.76)$ & $25.15 \pm 7.83(2.52 \pm 0.78)$ & $12.66 \pm 2.49(1.27 \pm 0.25)^{\mathrm{e}}$ \\
\hline $\begin{array}{l}\text { SAQ Expectations (range } 4 \text {, i.e., best, to } 20 \text {, i.e., worst), sum score } \\
\text { (mean, range } 1 \text {, i.e., best, to } 5 \text {, i.e., worst) }\end{array}$ & $13.36 \pm 4.86(3.34 \pm 1.21)$ & $13.43 \pm 4.87(3.36 \pm 1.22)$ & $6.53 \pm 3.43(1.63 \pm 0.86)^{\mathrm{e}}$ \\
\hline TAPS (range 5 , i.e., best, to 1 , i.e., worst) & $3.21 \pm 0.89$ & $3.07 \pm 0.91$ & $4.81 \pm 0.31^{\mathrm{e}}$ \\
\hline \multicolumn{4}{|l|}{ SRS 22-r score (range 5, i.e., best, to 1, i.e., worst) } \\
\hline Overall mean & $3.76 \pm 0.61$ & & \\
\hline Function & $3.89 \pm 0.65$ & & \\
\hline Pain & $3.90 \pm 0.90$ & & \\
\hline Self-image & $3.46 \pm 0.75$ & & \\
\hline Mental health & $3.77 \pm 0.78$ & & \\
\hline Satisfaction & $3.77 \pm 0.98$ & & \\
\hline Job-related worries (range 1 , i.e., best, to 5 , i.e., worst) & $2.42 \pm 1.24$ & & \\
\hline Social life-related worries (range 1 , i.e., best, to 5 , i.e., worst) & $2.75 \pm 1.29$ & & \\
\hline Overall stress (range 1, i.e., best, to 5 , i.e., worst) & $2.37 \pm 1.12$ & & \\
\hline VAS (pain) (range 0, i.e., best, to 10, i.e., worst) & $4.20 \pm 2.61$ & & \\
\hline PANAS (mood) (range 10 , i.e., best, to 50 , i.e., worst) & $13.94 \pm 5.41$ & & \\
\hline PHQ-9 (range 0, i.e., best, to 27, i.e., worst) & $4.95 \pm 4.63$ & & \\
\hline FKS (body dysmorphic disorder) (range 0, i.e., best, to 64 , i.e., worst) & $12.17 \pm 9.57$ & & \\
\hline BFI-S (neuroticism) (range 1, i.e., best to 7, i.e., worst) & $3.71 \pm 1.52$ & & \\
\hline PTQ (negative thinking) (range 0 , i.e., best, to 48 , i.e., worst) & $18.99 \pm 12.43$ & & \\
\hline WHO-5 (well-being) (range 25 , i.e., best, to 0 , i.e., worst) & $13.50 \pm 5.75(n=133)^{f}$ & & \\
\hline
\end{tabular}

BMI body mass index, SAQ Spinal Appearance Questionnaire, TAPS Trunk Appearance Perception Scale, SRS Scoliosis Research Society, VAS visual analogue scale, PANAS Positive and Negative Affect Schedule, PHQ-9 Patient Health Questionnaire, BFI-S neuroticism subscale of the Big Five Inventory-short, FKS Fragebogen körperdysmorpher Symptome, Questionnaire on Body Dysmorphic Symptoms, PTQ Perseverative Thinking Questionnaire, WHO-5 The WHO-5 Well-Being Index aBinomials included

${ }^{\mathrm{b}}$ Difference in weight is significant $(T=-2.63, \mathrm{df}=376, P<0.01)$; effect size is rather small $(d=-0.27)$

'Difference in height is not significant $(T=-0.50, \mathrm{df}=374, P=0.62)$

${ }^{\mathrm{d}}$ Difference in BMI is significant $(T=-2.24, \mathrm{df}=374, P=0.03)$; effect size is rather small $(d=-0.23)$

eDifferences between scoliosis subgroup and controls are significant with $P<.01$, see the "Discriminate validity" section

fOnly given during at the second time of measurement (retest) 
Table 2 Reliability of the SAQ and TAPS

\begin{tabular}{llllr}
\hline & SAQ Appearance & SAQ Expectations & SAQ total & TAPS \\
& & & score & $n$ \\
\hline Cronbach's $a$ & 0.93 & 0.86 & 0.91 & 0.86 \\
Test-retest reliability & $0.84^{* *}$ & $0.67^{* *}$ & $0.80^{* *}$ & $0.84^{* *}$ \\
\hline
\end{tabular}

All patients were invited to the retest, $n=133$ took part; ${ }^{* *} P<0.01$

the retest (T1 25.48 $\pm 7.87, \quad \mathrm{~T} 2 \quad 24.65 \pm 8.61 ; T=2.04$, $\mathrm{df}=132, P=0.04)$, and the TAPS score was slightly elevated in the retest (TAPS: T1 $3.05 \pm 0.93$, T2 $3.22 \pm 0.94$; $T=-3.82, \mathrm{df}=132, P<0.01)$. The retest reliability was good $(r \geq 0.80, P<0.01)$ for both measures, except for the SAQ Expectations scale $(r=0.67, P<0.01)$.

\section{Validity}

\section{Factorial validity}

An exploratory factor analysis (EFA) was used to investigate the structure of both measures. In the analysis of the SAQ, items 1 to 10 and 12 to 15 were included as proposed by Carreon et al. [8]. A value of 0.91 in the KaiserMeyer-Olkin (KMO) test indicated high suitability of the data for factor analysis [21]. Screeplot and factor solution reflected exactly the proposed structure of the SAQ with two factors, explaining $58.13 \%$ of variance. Factor loadings were between 0.47 and 0.89 for SAQ Appearance items and between 0.70 and 0.81 for SAQ Expectation items (see Additional file 1: Appendix 3). Both scales were correlated ( $r=0.46, P<0.01$, see Additional file 1: Appendix 4).

In the factor analysis of the TAPS, a value of 0.73 in the Kaiser-Meyer-Olkin (KMO) test indicated a middling suitability of the data for factor analysis [21]. The screeplot clearly indicated one single factor, explaining $67.02 \%$ of variance. Factor loadings were between 0.77 and 0.85 .

In sum, both measures showed clear factor solutions, which indicate high factorial validity.

\section{Convergent validity}

Convergent validity is the extent of agreement among theoretically highly related measures [22]. The SAQ and its two subscales showed significant correlations with each domain in the SRS 22-r, especially with the SRS self-image scale (see Table 3). Thus, a higher (poorer) SAQ score is associated with a lower (poorer) SRS 22-r score. The same pattern occurred for the TAPS (due to coding, correlations were positive).

Furthermore, high correlations were found for both measures with overall stress. In addition, worsening SAQ Appearance and TAPS scores were associated with higher Cobb angles, which was further investigated in a subgroup analysis (see below).

\section{Divergent validity}

Divergent validity refers to the degree of disagreement between theoretically unrelated (or less related) constructs
[22]. We expected the SAQ and the TAPS to correlate with the BMI at a low level. Surprisingly, we found relatively high correlations between the BMI and the SAQ Appearance scale $(r=0.41)$, the SAQ total score $(r=0.34)$, and the TAPS $(r=-0.35$; see Table 3$)$.

\section{Concurrent validity}

Concurrent validity refers to the ability of a measure to predict a concurrently assessed criterion [22]. The concurrently evaluated criteria (PANAS, PHQ-9, FKS, WHO-5, PTQ, and BFI-S) showed mostly moderate correlations with the SAQ Appearance, Expectations, and total score as well as the TAPS (see Table 3).

\section{Discriminant validity}

In the context of the present research, discriminant validity refers to the ability of a measure to distinguish between patients with scoliosis and individuals in a healthy control group. In a matched-pair analysis, the scoliosis group and the control group showed very clear differences in both measures: The average SAQ total score was twice as high in patients (see Table $1 ; F=474.62, \mathrm{df}=1,376, P<0.01$, $d=2.24)$, and the same applied to the SAQ Appearance scale $(F=436.72, \mathrm{df}=1,376, P<0.01, d=2.15)$ and the SAQ Expectations scale $(F=253.69, \mathrm{df}=1,376, P<0.01$, $d=1.64$ ). Likewise, the TAPS score was quite lower (i.e., worse) in patients (see Table $1, T=-24.78$, $\mathrm{df}=231.52$, $P<0.01, d=-2.56)$. The effect sizes $(d)^{1}$ were very large for all tested differences between patients and controls. Thus, both instruments are highly capable of distinguishing between scoliosis patients and healthy persons.

\section{Subgroup analysis: Cobb angle and age}

A subgroup analysis of patients with Cobb angles of less than $40^{\circ}$ and those with $\geq 40^{\circ}$ revealed significant differences for SAQ and TAPS, but not for the SAQ Expectations scale (see Table 4). Patients were divided into three age groups (14-17 years, $n=59 ; 18-45$ years, $n=130$; and 46 years and older, $n=66)$. The underage patients group as well as the young adults group showed lower (better) SAQ scores; however, the older patients group showed significantly higher (worse) SAQ scores. Answers given on the TAPS revealed a similar pattern.

\section{Discussion}

In line with prior research, both instruments showed very good results with respect to reliability in terms of 
Table 3 Correlations for convergent, divergent, and concurrent validity

\begin{tabular}{|c|c|c|c|c|c|}
\hline & SAQ Appearance & SAQ Expectations & $\begin{array}{l}\text { SAQ total } \\
\text { score }\end{array}$ & TAPS & $\mathrm{N}$ \\
\hline \multicolumn{6}{|l|}{ SRS 22-r } \\
\hline - Overall mean & $-0.49^{* *}$ & $-0.40^{* *}$ & $-0.53^{* *}$ & $0.48^{* *}$ & 255 \\
\hline - Function & $-0.40^{* *}$ & $-0.20^{* *}$ & $-0.37^{* *}$ & $0.40^{* *}$ & 255 \\
\hline - Pain & $-0.37^{* *}$ & $-0.24^{* *}$ & $-0.37^{* *}$ & $0.36^{* *}$ & 255 \\
\hline - Self-image & $-0.53^{* *}$ & $-0.49^{* *}$ & $-0.60^{* *}$ & $0.50^{* *}$ & 255 \\
\hline - Mental health & $-0.28^{* *}$ & $-0.31^{* *}$ & $-0.34^{* *}$ & $0.27^{* *}$ & 255 \\
\hline - Satisfaction & $-0.25^{* *}$ & $-0.28^{* *}$ & $-0.31^{* *}$ & $0.26^{* *}$ & 255 \\
\hline Job-related worries & $0.33^{* *}$ & $0.31^{* *}$ & $0.38^{* *}$ & $-0.33^{* *}$ & 255 \\
\hline Social life-related worries & $0.26^{* *}$ & $0.38^{* *}$ & $0.36^{* *}$ & $-0.27^{* *}$ & 255 \\
\hline Overall stress & $0.51^{* *}$ & $0.52^{* *}$ & $0.60^{* *}$ & $-0.51^{* *}$ & 255 \\
\hline VAS (pain) & $0.36^{* *}$ & $0.27^{* *}$ & $0.38^{* *}$ & $-0.33^{* *}$ & 255 \\
\hline Cobb angle & $0.55^{* *}$ & 0.10 & $0.44^{* *}$ & $-0.51^{* *}$ & 255 \\
\hline BMI & $0.41^{* *}$ & 0.11 & $0.34^{* *}$ & $-0.35^{* *}$ & 253 \\
\hline PANAS (mood) & $0.27^{* *}$ & $0.24^{* *}$ & $0.30^{* *}$ & $-0.26^{* *}$ & 255 \\
\hline PHQ-9 (depression) & $0.31^{* *}$ & $0.30^{* *}$ & $0.35^{* *}$ & $-0.26^{* *}$ & 255 \\
\hline FKS (body dysmorphic disorder) & $0.26^{* *}$ & $0.32^{* *}$ & $0.33^{* *}$ & $-0.24^{* *}$ & 255 \\
\hline WHO-5 (well-being) & $-0.38^{* *}$ & $-0.24^{* *}$ & $-0.38^{* *}$ & $0.33^{* *}$ & 133 \\
\hline PTQ (negative thinking) & 0.08 & $0.21^{* *}$ & $0.16^{*}$ & -0.10 & 255 \\
\hline BFI-S (neuroticism) & $0.16^{* *}$ & $0.20^{* *}$ & $0.21^{* *}$ & $-0.12^{*}$ & 255 \\
\hline
\end{tabular}

Convergent validation = SRS-22r, job-related worries, social life-related worries, overall stress, VAS, Cobb angle Divergent validation $=$ BMI

Concurrent validation = PANAS, PHQ-9, FKS, WHO-5, PTQ, BFI-S

${ }^{*} P<0.05,{ }^{* *} P<0.01$

Cronbach's $\alpha[5,8,12]$. The TAPS showed good test-retest reliability with a correlation of 0.84 . The retest was good for the SAQ Appearance scale (0.84) and the SAQ total score (0.80) but was lower for the SAQ Expectation scale (0.67). Similar values were also reached by Carreon et al. (0.81 for the SAQ Appearance scale and 0.89 for the SAQ total score), but better scores were achieved for the SAQ Expectations scale (0.91) [8]. This difference might be explained by the shorter time period of only
2 weeks between both investigations, in comparison to about 8 weeks after the first interrogation in our study. In light of these results, the long-term stability of the SAQ Expectation scale is at least in doubt and below the requirement $(r=0.7)$ for use in practice [23].

Regarding the convergent validity, the drawings in both questionnaires highly correlate with the Cobb angle (SAQ Appearance: $r=0.55$, TAPS: $r=-0.51$ ), which was also reported in earlier studies and is a lot higher than

Table 4 Subgroup and age analysis

\begin{tabular}{|c|c|c|c|c|}
\hline & SAQ Appearance & SAQ Expectations & SAQ total score & TAPS \\
\hline Cobb angle 10 to $39^{\circ}(n=133)$ & $20.62 \pm 4.83$ & $12.89 \pm 4.75$ & $33.51 \pm 8.22$ & $3.57 \pm 0.62$ \\
\hline Cobb angle $\geq 40^{\circ}(n=122)$ & $27.54 \pm 8.38$ & $13.88 \pm 4.94$ & $41.42 \pm 11.61$ & $2.81 \pm 0.97$ \\
\hline $\begin{array}{l}\text { Significance of differences in Cobb angle } \\
\text { groups }\end{array}$ & $\begin{array}{l}F=30.26, \mathrm{df}=1,252, P< \\
0.01\end{array}$ & $\begin{array}{l}F=1.11, \mathrm{df}=1,252, P= \\
0.29\end{array}$ & $\begin{array}{l}F=8.68, \mathrm{df}=1,252, P< \\
0.01\end{array}$ & $\begin{array}{l}F=23.11, \mathrm{df}=1,252, P< \\
0.01\end{array}$ \\
\hline Correlations with age & $0.58^{* *}$ & $0.18^{* *}$ & $0.49^{* *}$ & $-0.59^{* *}$ \\
\hline Age 14 to $<18$ years $(n=59)$ & $21.20 \pm 5.78$ & $13.92 \pm 4.68$ & $35.12 \pm 8.55$ & $3.57 \pm 0.64$ \\
\hline Age 18 to 45 years $(n=130)$ & $21.35 \pm 5.49$ & $12.18 \pm 4.81$ & $33.54 \pm 8.93$ & $3.48 \pm 0.69$ \\
\hline Age $\geq 46$ years $(n=66)$ & $31.44 \pm 7.64$ & $15.20 \pm 4.50$ & $46.64 \pm 10.24$ & $2.35 \pm 0.89$ \\
\hline Significance of differences in age groups & $\begin{array}{l}F=40.41, \mathrm{df}=1,252, P< \\
0.01\end{array}$ & $\begin{array}{l}F=1.16, d f=1,252, P= \\
0.28\end{array}$ & $\begin{array}{l}F=10.89, \mathrm{df}=1,252, P< \\
0.01\end{array}$ & $\begin{array}{l}F=44.44, \mathrm{df}=1,252, P< \\
0.01\end{array}$ \\
\hline
\end{tabular}

Means and standard deviations of SAQ sum scores and TAPS mean score are presented; for displayed correlations: ${ }^{*} P<0.01 ; F$ values result from a MANCOVA with Cobb angle as independent variable, age as covariate, and SAQ and TAPS as dependent variables 
values found for verbal questionnaires such as the G-BIDQ-S $(r=0.30)$ or G-QLPSD $(r=0.28)[12,19,20]$. The correlation between Cobb angle and both the SAQ Appearance scale and TAPS was even higher than in Carreon et al. (SAQ, $r=0.36$ ) and Misterska et al. (TAPS, $r=-0.44)[8,10]$. Thus, the use of such drawings might reflect the scoliosis perception of patients much better than verbal questions.

There were also high correlations between the SRS 22-r total score and both questionnaires (SAQ total score $r=-0.63$ vs. TAPS $r=0.48)$. The highest correlations were reported between the self-image domain of the SRS and the SAQ Appearance scale $(r=-0.53)$ as well as the TAPS $(r=0.50)$. These results match the findings of Carreon et al. (SAQ $r=-0.39$ ) and Bago et al. (TAPS $r=0.54$ ) $[5,8]$ and could be explained by the fact that both measures are focused on patients' body image. Moreover, the overall stress item showed high correlations with both instruments (SAQ, $r=0.60$ vs. TAPS, $r=-0.51$ ), indicating a psychological burden on the patients. The study also revealed evidence for very high discriminant validity: Patients with scoliosis had a significantly higher (worse) SAQ score on both scales as well as for the total score. Similarly, the TAPS score is lower (worse) in patients. This corresponds with earlier findings that patients with scoliosis have a worse body image than healthy controls [19]. Taking everything into account, the SAQ and TAPS showed similar results with regard to various correlations in validation.

The two subgroups of patients with higher and lower Cobb angles (cut-off $=40^{\circ}$ according to the international literature, which recommends different treatments for patients below and above $40^{\circ}$ ) showed similar results on the SAQ Expectations scale. However, patients with more severe deformities had worse scores in the SAQ Appearance scale and the TAPS, which reflects earlier findings in similar studies [10, 12, 19]. Regarding patient age, there seemed to be no relevant difference between underage patients and adults up to the age of 45 . However, older scoliosis patients reported worse SAQ and TAPS scores. To date, no studies had been performed concerning this issue; therefore, further research is needed.

With a total number of 255 patients with idiopathic scoliosis, this is the largest collective that has ever answered both the SAQ and the TAPS for the purpose of comparison. Such a sample provides a sound basis for stable estimates of correlations [24]. With regard to factor analysis, most sample size requirements for producing a reliable factor solution were met, although a definitive identification of a multifactorial model might require larger sample sizes $[25,26]$. Two further limitations might be considered when interpreting the present study: First, data were acquired via a web-based study relying on self-reports, and no radiographic data for patients were taken into account-as it was most feasible, we only used the main Cobb angle. Second, there might be additional constructs relevant for scoliosis patients' body image and well-being not covered in the present validation of SAQ and TAPS.

Finally, we aimed to answer the question of which instrument-the SAQ or TAPS—should be recommended for clinical or scientific use. For scientific projects, both could be of value. In clinical everyday situations, the number of questionnaires should be limited due to time restrictions and practicability. Based on the present findings, to investigate patients' subjective body image, we clearly recommend using the TAPS. Thus, here, we confirm and extend the results of the comparison study performed by Matamalas et al. [12]. The reasons for our recommendation are that, first, the SAQ Appearance scale and TAPS are highly correlated $(r=0.85, P<0.01)$, but the TAPS only consists of three items vs. the ten items on the SAQ's Appearance scale. Thus, less time is needed to fill out the questionnaire while there is no loss in psychometric quality. Second, as Carreon et al. recommend using only four out of the 22 remaining items of the SAQ [8], using other measures instead of the SAQ Expectations scale seems more efficient and promising. Patient expectations and worries could be better assessed with scales such as the BIDQ-S [2, 19], and scoliosis patients' quality of life could be better assessed with a measure such as the QLPSD [3, 20].

In general, for treating patients in research, combining different measures is useful in an extensive anamnesis. In doing so, patient questionnaires are of high value for refining a medical diagnosis, understanding a patient's needs, and assessing the potential need to offer psychotherapeutic support. For clinical use, a compilation of questionnaires is recommended depending on the goals of the caregiver. As a general recommendation, we suggest applying a combination of the TAPS, BIDQ-S, and SRS-22 or alternatively QLPSD as screening instruments for scoliosis patients about twice a year.

\section{Conclusions}

In respect to our first aim, we can state that both instruments show high psychometric qualities; only the stability of the SAQ Expectations scale seems to be impaired. For our second aim, comparing the instruments, we clearly recommend using the TAPS for future clinical workups and research.

\section{Endnotes}

${ }^{1}$ According to the guidelines provided by Cohen, standardized mean differences of $0.2,0.5$, and 0.8 and more are considered to represent small, medium, and large effects, respectively [27]. 


\section{Additional file}

Additional file 1: Online supplement. (DOCX 4202 kb)

\begin{abstract}
Abbreviations
BFI-S: GSOEP Big Five Inventory; BMI: Body mass index; FKS: Fragebogen körperdysmorpher Symptome [Questionnaire on Body Dysmorphic Symptoms]; G-BIDQ-S: German Body Image Disturbance QuestionnaireScoliosis; G-QLPSD: German Quality of Life Profile for Spinal Disorders; PANAS: Positive and Negative Affect Schedule; PHQ-9: Patient Health Questionnaire; PTQ: Perseverative Thinking Questionnaire; SAQ: Spinal Appearance Questionnaire; SRS 22-r: Scoliosis Research Society 22-r; TAPS: Trunk Appearance Perception Scale; VAS: Visual analogue scale; WRVAS: Walter Reed Visual Assessment Scale
\end{abstract}

\section{Acknowledgements}

We would like to thank Jan Henrik Terheyden for his support in acquiring patients and Friederike Jansen for her support in sampling and data preparation for analyses. We would also like to thank Dr. Celeste Brennecka for proofreading the manuscript as well as Dr. Michael Robertson and Petra Hölzle for professionally translating the Spinal Appearance Questionnaire from English to German and vice versa.

\section{Funding}

We acknowledge support from the Open Access Publication Fund of the University of Muenster.

\section{Availability of data and materials}

The raw data include confidential data of scoliosis patients, and no consent for an open publication of data was explicitly given. Thus, data could not be provided openly. The datasets used and analyzed during the current study are available from the corresponding author on reasonable request.

\section{Authors' contributions}

MT conceived, designed and performed the study, contributed materials/ analysis tools, analyzed the data, prepared the tables, drafted the work, and revised it critically for important content. MW conceived, designed and performed the study, contributed materials/analysis tools, drafted the work, and revised it critically for important content. PB conceived, designed and performed the study, and contributed materials/analysis tools. GG contributed materials/analysis tools. TS conceived and designed the study, contributed materials/analysis tools, drafted the work, and revised it critically for important content. All authors read and approved the final manuscript.

\section{Ethics approval and consent to participate}

Informed consent was obtained from all individual participants included in the study. All participants were instructed at the beginning of the online survey about the purpose and responsible researcher (including contact opportunities), that all data will be used only for academic purposes, and that all participants will remain completely anonymous in this study. We asked for consent twice: (1) On the second and third page of the web survey information, consent forms were given. (2) Additionally, all participants were again asked for consent at the end of the study (thus, after they have seen all relevant questions). At this point, participants had the opportunity to withdraw their consent with a self-exclusion item. The ethics committee of the Medical Faculty of the University of Münster approved the study (ref. no. 2014-660-f-S).

\section{Consent for publication}

The study was performed in a web-based format. Thus, all participants were instructed via the online survey website about the purpose and responsible researcher (including contact opportunities), that all data will be used only for academic purposes, and that all participants will remain completely anonymous in this study. We asked for consent twice: (1) On the second and third page of the web survey information, consent forms were given. Consent forms were draw up in consultation with the ethics committee of the Medical Faculty of the University of Münster and approved for the study by the ethics committee (ref. no. 2014-660-f-S). Forms were stored electronically, as the study was performed in a web-based manner. If needed, English translations of German forms can be provided via the corresponding author. (2) Additionally, all participants were again asked for consent at the end of the study (thus, after they have seen all relevant questions). Participants had the opportunity to withdraw their consent (and consequently delete all of their data) with a self-exclusion item at the end of the study (see the "Materials and methods" section of our manuscript). This question was given automatically and individually.

In line with the standards provided by the German Council for Market and Social Research (see http://rat-marktforschung.de/fileadmin/user_upload/pdf/ R05_RDMS.pdf) and according to the German law effective at the time of the study, parental consent was not obtained for participants aged between 14 und 17.

\section{Competing interests}

The authors declare that they have no competing interests.

\section{Publisher's Note}

Springer Nature remains neutral with regard to jurisdictional claims in published maps and institutional affiliations.

\section{Author details}

${ }^{1}$ Department of Psychology, University of Münster, Fliednerstr. 21, 48149 Münster, Germany. ${ }^{2}$ St. Josef-Hospital, Ruhr University Bochum, Bochum, Germany. ${ }^{3}$ Universitätsklinikum Münster, Münster, Germany.

\section{Received: 30 August 2018 Accepted: 17 October 2018}

Published online: 30 October 2018

\section{References}

1. Niemeyer T, Schubert C, Halm HF, Herberts T, Leichtle C, Gesicki M. Validity and reliability of an adapted German version of scoliosis research society-22 questionnaire. Spine. 2009;34:818-21.

2. Auerbach JD, Lonner BS, Crerand CE, Shah SA, Flynn JM, Bastrom T, Penn P, Ahn J, Toombs C, Bharucha N, et al. Body image in patients with adolescent idiopathic scoliosis: validation of the body image disturbance questionnaire--scoliosis version. J Bone Joint Surg Am. 2014;96:e61-1-8.

3. Climent JM, Reig A, Sanchez J, Roda C. Construction and validation of a specific quality of life instrument for adolescents with spine deformities. Spine. 1995;20:2006-11.

4. Sanders JO, Harrast JJ, Kuklo TR, Polly DW, Bridwell KH, Diab M, Dormans JP, Drummond DS, Emans JB, Johnston CE, et al. The Spinal Appearance Questionnaire: results of reliability, validity, and responsiveness testing in patients with idiopathic scoliosis. Spine. 2007;32:2719-22.

5. Bago J, Sanchez-Raya J, Perez-Grueso FJS, Climent JM. The Trunk Appearance Perception Scale (TAPS): a new tool to evaluate subjective impression of trunk deformity in patients with idiopathic scoliosis. Scoliosis. 2010;5:6.

6. Sanders JO, Polly DW Jr, Cats-Baril W, Jones J, Lenke LG, O'Brien MF, Stephens Richards B, Sucato DJ. Analysis of patient and parent assessment of deformity in idiopathic scoliosis using the Walter Reed Visual Assessment Scale. Spine. 2003;28:2158-63.

7. Mulcahey MJ, Chafetz RS, Santangelo AM, Costello K, Merenda LA, Calhoun C, Samdani AF, Betz RR. Cognitive testing of the spinal appearance questionnaire with typically developing youth and youth with idiopathic scoliosis. J Pediatr Orthop. 2011;31:661-7.

8. Carreon LY, Sanders JO, Polly DW, Sucato DJ, Parent S, Roy-Beaudry M, Hopkins J, McClung A, Bratcher KR, Diamond BE. Spinal appearance questionnaire: factor analysis, scoring, reliability, and validity testing. Spine. 2011;36:4

9. Bagó J, Climent JM, Pérez-Grueso FJS, Pellisé F. Outcome instruments to assess scoliosis surgery. Eur Spine J. 22(Suppl 2):195-202.

10. Misterska E, Glowacki M, Latuszewska J, Adamczyk K. Perception of stress level, trunk appearance, body function and mental health in females with adolescent idiopathic scoliosis treated conservatively: a longitudinal analysis. Qual Life Res. 2013;22:1633-45.

11. Rigo M, D'agata E, Jelacic M. Trunk Appearance Perception Scale (TAPS) discrepancy between scoliosis children and their parents influence the SRS22 secore. Scoliosis. 2012;7:03.

12. Matamalas A, Bago J, D'Agata E, Pellise F. Body image in idiopathic scoliosis: a comparison study of psychometric properties between four patientreported outcome instruments. Health Qual Life Outcomes. 2014;12:81.

13. Kroenke K, Spitzer RL, Williams JBW. The PHQ-9: validity of a brief depression severity measure. J Gen Intern Med. 2001;16(9):606-13. 
14. Watson D, Clark LA, Tellegen A. Development and validation of brief measures of positive and negative affect. The PANAS scales. J Pers Soc Psychol. 1988;54:1063-70.

15. Buhlmann U, Wilhelm S, Glaesmer H, Brähler E, Rief W. Fragebogen körperdysmorpher Symptome (FKS). Ein Screening-Instrument Verhaltenstherapie. 2009;19:237-42.

16. Schupp J, Gerlitz JY. Big Five Inventory-SOEP (BFI-S). Zusammenstellung sozialwissenschaftlicher Items und Skalen. 2014. https://doi.org/10.6102/zis54.

17. Ehring T, Zetsche U, Weidacker K, Wahl K, Schonfeld S, Ehlers A. The Perseverative Thinking Questionnaire (PTQ): validation of a contentindependent measure of repetitive negative thinking. J Behav Ther Exp Psychiatry. 2011;42:225-32

18. Topp CW, Østergaard SD, Søndergaard S, Bech P. The WHO-5 Well-Being Index: a systematic review of the literature. Psychother Psychosom. 2015;84: 167-76.

19. Wetterkamp M, Thielsch MT, Gosheger G, Boertz P, Terheyden, JH, Schulte TL. German Validation of the BIDQ-S questionnaire on body image disturbance in idiopathic scoliosis. Eur Spine J. 2017;26(2):309-15.

20. Schulte TL, Thielsch MT, Gosheger G, Boertz P, Terheyden JH, Wetterkamp M. German Validation of the Quality of Life Profile for Spinal Disorders (QLPSD). Eur Spine J. 2018;27(1):83-92.

21. Dziuban CD, Shirkey EC. When is a correlation matrix appropriate for factor analysis? Some decision rules. Psychol Bull. 1974;81:358-61.

22. Nunnally JC, Bernstein IH. Psychometric theory. 3rd ed. New York: McGrawHill; 1994.

23. Cook DA, Beckman TJ. Current concepts in validity and reliability for psychometric instruments: theory and application. Am J Med. 2006;119:166. e7-166.e16.

24. Schönbrodt FD, Perugini M. At what sample size do correlations stabilize? J Res Pers. 2013:47:609-12.

25. Hirschfeld G, von Brachel R, Thielsch MT. Selecting items for Big Five questionnaires. At what sample size do factor loadings stabilize? J Res Pers. 2014:53:54-63.

26. Beavers AS, Lounsbury JW, Richards JK, Huck SW, Skolits GJ, Esquivel SL. Practical Considerations for Using Exploratory Factor Analysis in Educational Research. Pract Assess Res Eval. 2013;18(6). Available at: https://www. pareonline.net/getvn.asp? $v=18 \& n=6$.

27. Cohen J. Statistical power analysis for the behavioral sciences. 2nd ed. Hillsdale: Erlbaum; 1988.

Ready to submit your research? Choose BMC and benefit from:

- fast, convenient online submission

- thorough peer review by experienced researchers in your field

- rapid publication on acceptance

- support for research data, including large and complex data types

- gold Open Access which fosters wider collaboration and increased citations

- maximum visibility for your research: over $100 \mathrm{M}$ website views per year

At BMC, research is always in progress.

Learn more biomedcentral.com/submissions 